\title{
TRYPTAMINERGIC MECHANISM PARTICIPATING IN INDUCTION OF VASOCONSTRICTION BY ADENINE NUCLEOTIDES, ADENOSINE, IMP AND INOSINE IN THE ISOLATED AND BLOOD-PERFUSED HINDLIMB PREPARATION OF THE RAT
}

\author{
Kazushige SAKAI \\ Department of Pharmacology, Research Laboratories, \\ C'mugi Pharmacentical Co., l.td., Toshima-kin, Tokyo 17l, Japan
}

Accepted Iicbruary 8, 1978

\begin{abstract}
The isolated right hindlimb of the recipient rat was perfused at a constant flow rate through the femoral artery with heparinized blood from the carotid artery of a donor. The preparations were under a $99.0-t 0.8 \mathrm{mmHg}$ of mean perfusion pressure $(\mathrm{N}==63)$ and $3.3 ! 0.1 \mathrm{ml} / \mathrm{min}$ of blood flow through the right femoral artery. The actions of adenosine, adenosine tri-, die- and monophosphate, inosine monophosphate and inosine on the femoral vascular bed were investigated, respectively. These substances injected into the femoral artery, with the exception of inosine, caused a dose-dependent vasoconstriction always preceded by a temporal vasodilatation. Inosine induced only a prompt vasoconstriction. The valsoconstrictor responses to these substances were diminished or reserted to vasodilator ones after repeated administrations and such were signilicantly prevented by pretreatment with either reserpine or methysergide. These resulls indicate that all the purines tested induce a vasoconstriction in the femoral valscular bed of the rat througl a common (tryptaminergic) mechanism and that such seem to be potent releasers of 5-hydroxytryptamine from peripheral tryptaminergic storage sites.
\end{abstract}

Since Drury and Szent-Györgyi (1) first investigated the actions of adenosine and adenine nuclcotides on the cardiovascular system, considerable interest has been focused on the mode of actions of these substances in the peripheral circulation. It has been reported that intra-arterial injection of these substanecs causes vasodilatation on the femoral vascular bed of the cat (2) and dog (3-6).

Recently, however, it was reported that either adenosine or inosine given into the femoral artery of the rat caused a prominent vasoconstriction which was associated with a tryptaminergic mechanism (7-8). Adenine nucleotides are hydrolysed in blood and tissues and converted rapidly to adenosine and/or inosine (9-11). It was of interest, therefore, to examine whether adenine nucleotides and inosine monophosphate also induce a constriction of the femoral vasculature of the rat through a tryptaminergic mechanism.

The present study, using isolated and cross-circulated hindlimb preparation of the rat, provides pharmacological evidence that adenine and hypoxanthine series release 5-hydroxytryptamine from the peripheral stores, resulting in a vasoconstriction of the femoral artery.

\section{MATERIAIS AND METHODS}

Male Splague-Dawley rats were allowed free access to food and water overnight prior 
to experiments.

\section{Surgical procedures}

Donor rats $(550-750 \mathrm{~g})$ were anaesthetized initially with pentobarbital sodium $(65 \mathrm{mg}$ / $\mathrm{kg}$ i.p.), and anaesthesia was maintained hourly with sustaining doses of urethane ( $400 \mathrm{mg}$ ! $\mathrm{kg} \mathrm{s.c.).} \mathrm{The} \mathrm{right} \mathrm{jugular} \mathrm{vein} \mathrm{and} \mathrm{carotid} \mathrm{artery} \mathrm{were} \mathrm{cannulated} \mathrm{with} \mathrm{polyethylene}$ cannulae. Heparin sodium $(1000 \mathrm{U} / \mathrm{kg})$ was injected into the femoral vein, and the systemic blood pressure was measured from the left femoral artery with a pressure transducer (Nihon Kohden, RP-5). The carotid and jugular cannulac of the donor were connected to the perfusion circuit after the circuit had been filled with about $10 \mathrm{ml}$ of blood freshly drawn from heparinized rats.

Recipient rats ( $300-350 \mathrm{~g}$ ), which were anaesthetized with pentobarbital sodium ( $65 \mathrm{mg} /$ $\mathrm{kg}$ i.p.), were prepared for perfusion of the right hindlimb. The right fenoral artery and vein were dissected free, and loops of thread for ligatures were placed around the blood vessels. The muscles such as $M$. rectus femoris, $M$. psoas longus and $M$. gracilis were carefully ligated and cut around the caput femoris. The femoral and sciatic nerves were also severed. Then, an abdominal midline incision was made and the intestine was moved toward the left for exposure of the right common iliac artery and vein near the origin of the abdominal aorta and inferior vena cava. After heparin sodium $(1000 \mathrm{U} / \mathrm{kg})$ was injected into the left femoral vein, a venous cannula (ID $1 \mathrm{~mm}$, OD $1.5 \mathrm{~mm}$ ) was inserted into the femoral vein via the common iliac vein. Subsequently, an arterial metal cannula (ID $0.4 \mathrm{~mm}$, OD $0.6 \mathrm{~mm}$ ) was introduced into the femoral artery via the common iliac artery. Immediately after the right hindlimb of the recipient was isolated completely from the body by cutting the bone at the caput femoris, the blood from the right carotid artery of the donor was conducted into the femoral artery of the isolated right hindlimb of the recipient by means of a peristaltic pump (Mitsumi Science, S.I-1210). The pump was precalibrated and rechecked at the end of the experiment. A square wave electromagnetic flowmeter (Nihon Kohden, MF-25) was used for the measurement of the femoral blood inflow. Perfusion pressure was measured with a pressure transducer (Nihon Kohden, RP-5) from a side arm near the arterial cannula. Recordings were made on an ink-writing rectigraph (TOA Electronics, EPR-3T). The experimental set-up is illustrated schematically in Fig. 1A.

The perfusing blood from the carotid cannula of the donor first flowed into a small glass bottle. The volume of blood in the bottle was maintained constant by adjustment with a small screw clamp. The venous outflow from the femoral vein of the isolated limb of the recipient was collected in a venous reservoir and in turn returned to the jugular vein of the donor by $15 \mathrm{~cm}$ drop of hydrostatic pressure. The donor and the isolated right hindlimb of the recipient, respectively, were placed on heating tables and the body temperature was maintained between 36 and $38^{\circ} \mathrm{C}$ throughout the experiment. Moreover, the surface of the hindlimb was covered with liquid paraffin and warmed by radiant heat from a lamp.

Reserpine was given s.e. twice in dose of $5 \mathrm{mg} / \mathrm{kg} 48$ and $24 \mathrm{~h}$, respectively, prior to the experiment. 

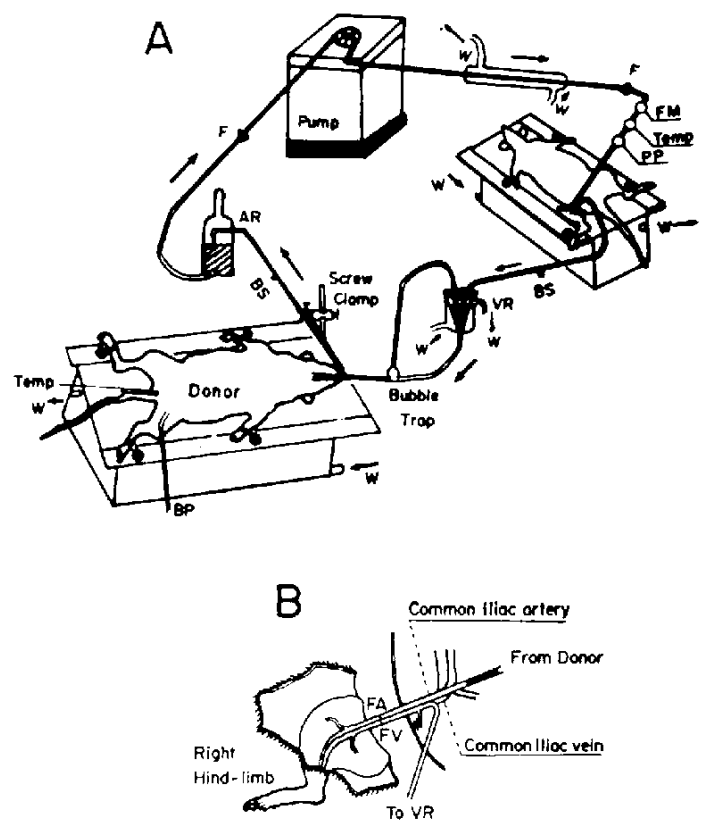

Fig. 1. Schematic diagram of the preparation (A in the Figurc). Blood flows from the carotid artery of a donor into an arterial reservoir (AR) and is constantly pumped to the femoral artery (FA) of the isolated right hindlimb of the recipient ( $B$ in the Figure). Femoral venous blood is returned via a venous reservoir (VR) to the jugular vein of the donor. BP, systemic blood pressure; Temp, thermometer; W, circulating warming water; AR, arterial reservoir; F, filter (SartoriusMembranfilter GMBH, West Germany); Pump, peristaltic pump; BS, blood sampling: FM, electromagnetic flowmeter; $P P$, perfusion pressure: $F A$, femoral artery: $\Gamma V$, remoral vein.

Drugs

The drugs used were adenosine-5'-triphosphate disodium (ATP), adenosine-5'-diphosphate sodium (ADP), adenosine-5'-monophosphate sodium (AMP), inosine-5'-monophosphate sodium (IMP), adenosine, inosine and 5-hydroxytryptamine creatinine sulphate (5-HT) (Sigma), ( $t$ )-noradrenaline hydrochloride (Sankyo), methysergide tartrate (Sandoz), tyramine hydrochloride (Tokyo Kasei) and reserpine (Apoplon ${ }^{\circledR}$, Daiichi Seiyaku). Drugs were dissolved in $0.9 \%$ saline as stock solutions and were diluted with $0.9 \%$ saline just before use. Microsyringes (Jintan Terumo Co.) were used for close-arterially injecting a volume of $10,1 \mathrm{in}$ a period of $4 \mathrm{sec}$ into a rubber tube connected to the shank of the polyethylene cannula. Doses of 5-HT, tyramine, noradrenaline and methysergide refer to their salts and of the other substances to their bases. Increases (vasoconstriction) or decreases (vasodilatation) in the perfusion pressure caused by drugs were taken as drug responses, as the perfusion rate was constant.

\section{Statistical analysis}

Values in the text are means $\mathrm{S}$.E. The statistical significance of the differences between mean values was analysed using Student's $t$-test and expressed as $P$ values. 


\section{RESULTS}

Blood flow through the femoral artery

Within 30 min after the beginning of perfusion, the mean perfusion pressure reached a constant level of $99.0 \pm 0.8 \mathrm{mmHg}(\mathrm{N}=63)$. The preparations then had a femoral blood flow of $3.3+0.1 \mathrm{ml} / \mathrm{min}$ and such remained stable for $3 \mathrm{hr}$ or more. The average wet weight of the perfused hindlimb measured at the end of the experiment was $29.6-0.3 \mathrm{~g}$, and the flow rate per unit of wet weight was $10.1 \pm 0.4 \mathrm{ml} \mathrm{min}^{-1} .100 \mathrm{~g}^{-1}$.

Effects of ATP, ADP, AMP, IMP, adenosine and inosine on the femoral vascular bed

Single injections of increasing doses $\left(3 \times 10^{-9}-10^{-6}\right.$ moles) of either ATP, ADP, AMP, IMP or adenosine into the femoral artery produced a prominent vasoconstriction preceded

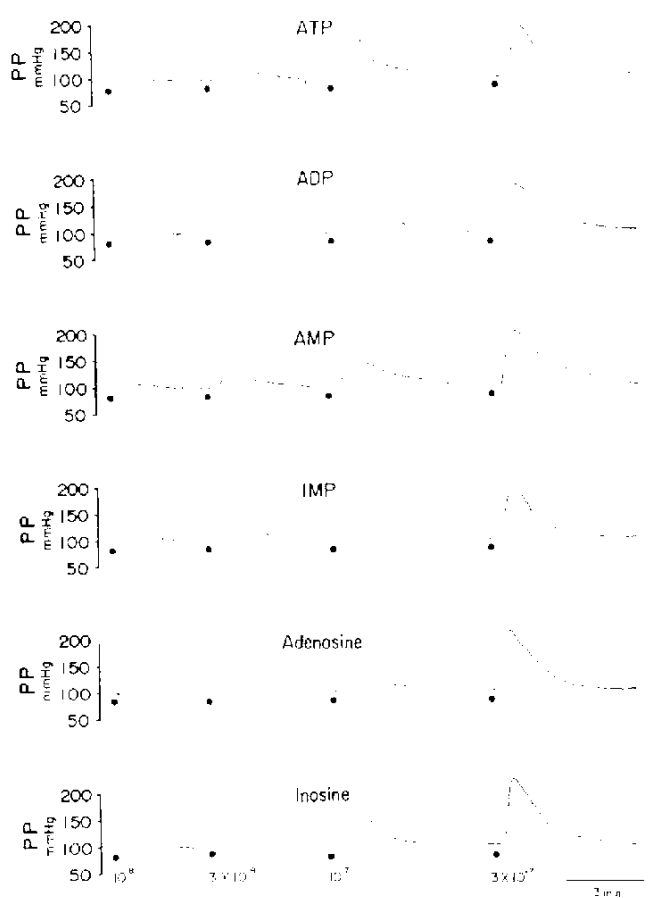

A

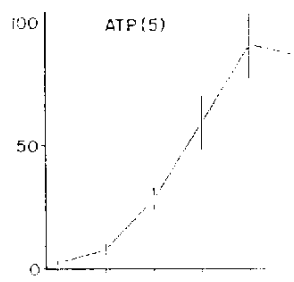

$\operatorname{ADP}\left(\bar{s}_{\mathrm{j}}\right)$
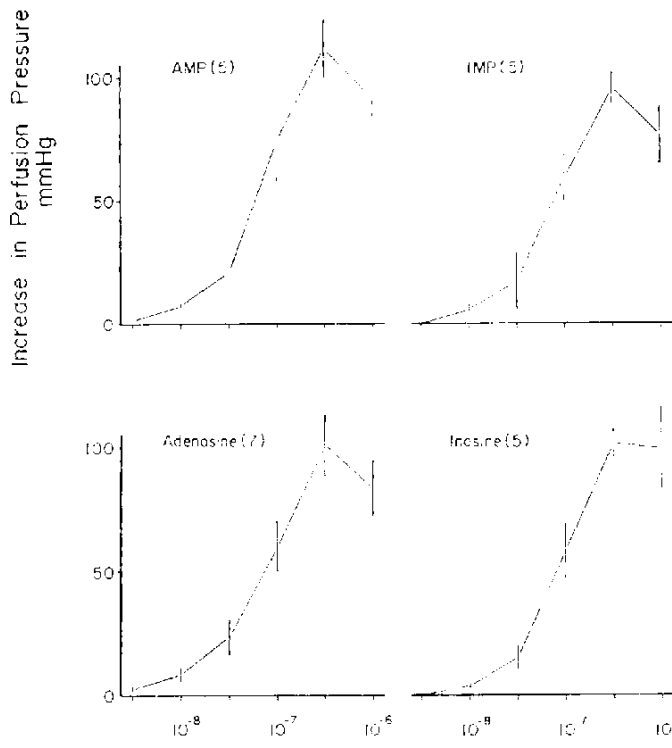

[resire:s\}

Dose (mol)

B

FIG. 2. Dose-response relations for vascular effects of ATP, ADP, AMP, IMP, adenosine or inosine. Each substance was injected into the femoral artery in individual preparations. The differenees in the inital perfusion pressure (PP) among these preparations were not significant. A) Original tracings. All doses are expressed in moles. B) Dose-response curves for increase in perfusion pressure of the fenural artery to six purines tested. Vertical bars represent means: S.E. and the number of experiments is given in parentheses. Initial perfusion pressure, $97.6 \pm 1.1 \mathrm{mmHg}(\mathrm{N}=32)$. 
by a temporal vasodilatation (Fig. $2 \mathrm{~A})$. Inosine $\left(3 \times 10^{-9}-10^{-5}\right.$ moles) induced only a vasoconstriction. The vasoconstrictor responses to these substances were increased in a dose-dependent manner in doses of $3 \times 10^{-9}$ to $3 \times 10^{-7}$ moles, and reached the maximum at $3 \times 10^{-}$moles, and at $10^{-5}$ moles the vasoconstrictor responses tended to decrease (Fig. 2B).

Responses of the femoral vascular bed to repeated administrations of either ATP, ADP, AMP, IMP, adenosine or inosine

All the purines tested were injected into the femoral artery in an equimolar dose $\left(10^{-6}\right.$

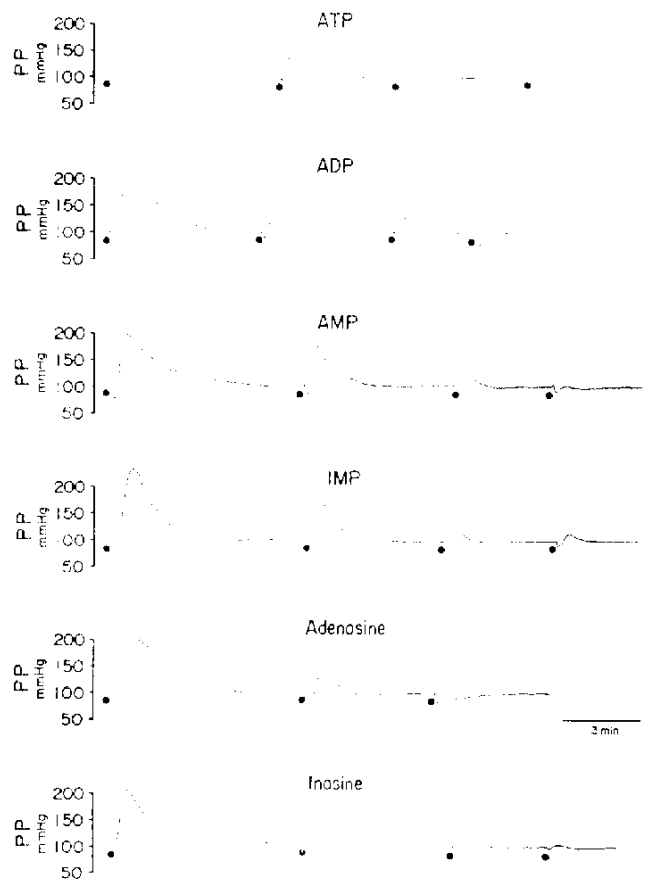

$A$
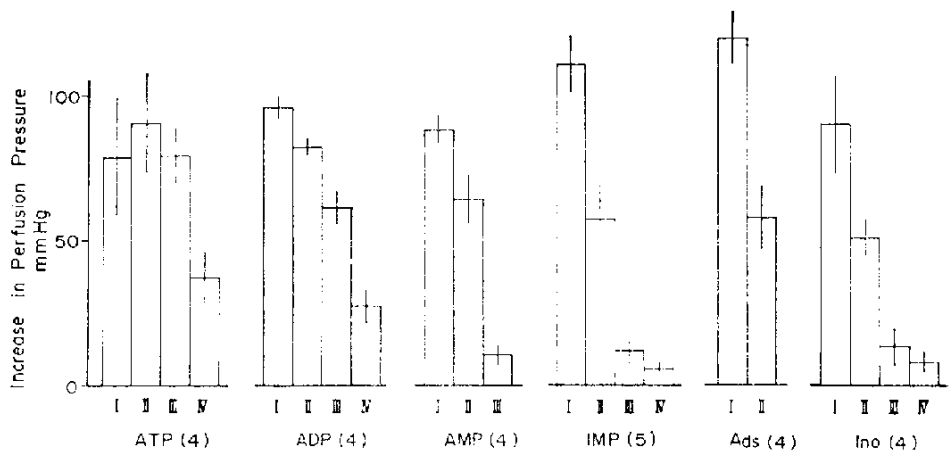

B

Fir. 3. Response of the femoral vascular bed to repcated administrations $\left(10^{-6}\right.$ moles $)$ of either ATP, ADP, AMP, IMP, adenosine (Ads) or inosine (Ino). Further explanation is described in the equal for Fig. 2. 
moles). The first administration (I) of these substances caused a marked and long-lasting vasoconstriction. When the responses to the preceding administrations had worn off completely, the same dose (10 ${ }^{\circ}$ moles) of these substances was successively injected, respectively. As shown in Fig. $3 \mathrm{~A}$ and B, the vasoconstrictor responses to these substances were diminished progressively after repeated administrations, and finally almost disappeared or vasodilator responses were seen.

When the intensity of vasoconstrictor responses to the first administrations of these substances was compared, there was statistically no significant difference (Fig. 3B).

Vasoconstrictor potencies of ATP, ADP, AMP, IMP, adenosine and inosine in the femoral vascular bed

As shown in Fig. 2B, all the purines tested produced dose-dependent vasoconstrictor responses within the dose range of $3 \times 10^{-9}, 3 \times 10^{-5}$ moles, but at $10^{-6}$ moles the dose-

Table 1. FD50 values for vasoconstriction induced by the purines tested on the femoral vascular bed

\begin{tabular}{lcc}
\hline Derivative & $\begin{array}{c}\text { Negative log mol ED50 } \\
\text { (moles) }\end{array}$ & No. of experiments \\
\hdashline ATP & $7.21 \div 0.08$ & 5 \\
ADP & $7.29 \div 0.03$ & 5 \\
AMP & $7.12 \div 0.07$ & 5 \\
IMP & $7.20 \div 0.14$ & 5 \\
Adenosine & $7.10 \div 0.07$ & 7 \\
lnosine & $7.05 \div 0.10$ & 5
\end{tabular}

ED50 values were obtained from the dose-response curves reconstructed in such a way that the responses to $3 \% 10^{-7}$ moles of each were taken as a $100 \%$ maximum vasoconstrictor ones, and are expressed as the negative logarithm of the molar duse of the purines tested producing a $50 \%$ maxinum vasoconstriction. Values are means S.E.
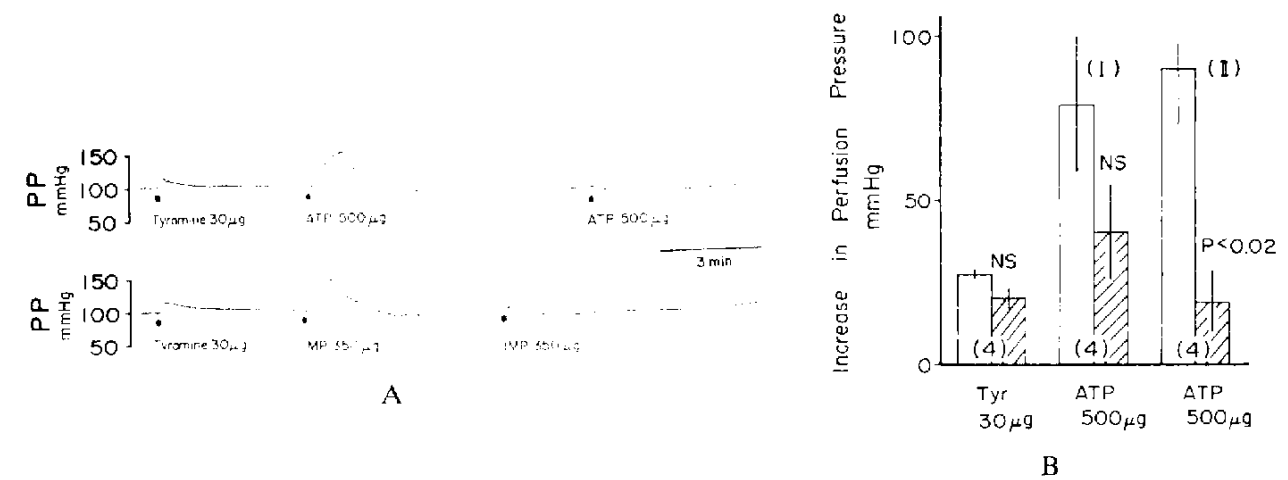

FiG. 4. Responses of the femoral vascular bed to tyramine (Tyr) and ATP or IMP in reserpinized preparations. A) Original tracings. Compare with the responses to the same dose of ATP or IMP in untreated preparations (sce Fig. 3A). B) Sumnarized data. Open columns: untreated; hatched columns: treated with reserpine. The results of IMP $(\mathrm{N}-2)$ are not shown. N.S., not significant. Other details as in Fig. 2. 
response curves fell. Thus, it was reasonable to consider that these substances consistently caused a $100 \%$ maximum constriction of the femoral vasculature at the dose of $3 \times 10^{-7}$ moles.

The ED50 (the negative logarithm of the molar dose producing a $50 \%$ maximum vasoconstriction) was determined by reconstructing dose-vasoconstrictor response curves for each substance in a percentage of the maximum response (Table 1). There was no significant difference in the potencies of these substances inducing the vasoconstrictor responses.

Effect of pretreatment with reserpine on the vasoconstrictor responses to ATP and IMP

A single injection of ATP $\left(500 \mu \mathrm{g} ; 10^{-6}\right.$ moles) or IMP ( $350 \mu \mathrm{g} ; 10^{-6}$ moles) was given to a single preparation. Although the vasoconstrictor response to the first single injection (I) of either ATP or IMP into the femoral artery in reserpine-pretreated animals was not significantly different from the vasoconstrictor response to the same dose of ATP or IMP in untreated preparations (Fig. $3 \mathrm{~A}$ and $\mathrm{B}$ ), the vasoconstrictor response to the second injection (II) was diminished to a greater extent than that in untreated preparations (Fig. 4A and $\mathrm{B})$. The response to tyramine $(30 \mu \mathrm{g})$ was considerably sustained in reserpinized

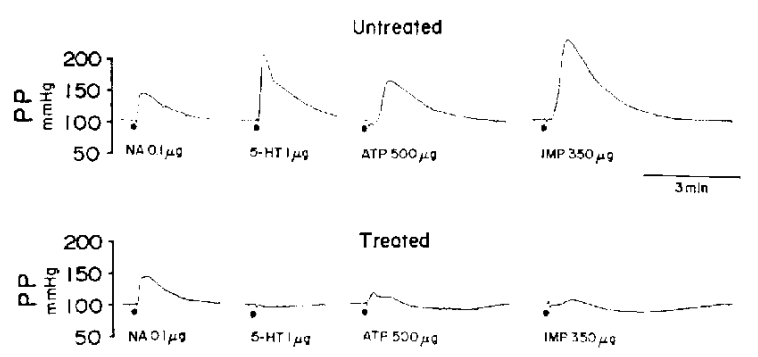

A

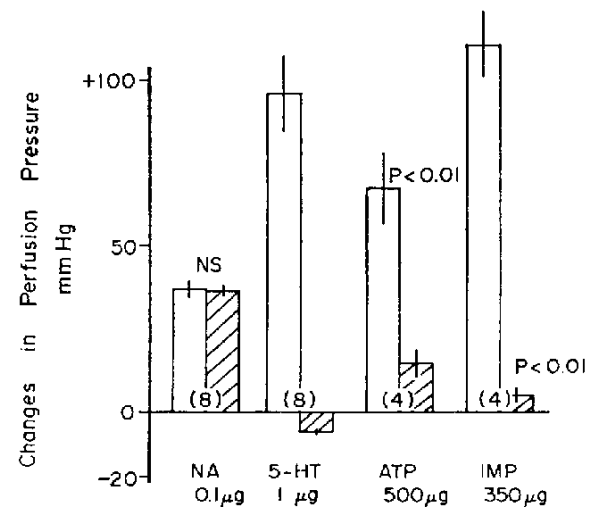

B

FIG, 5. Effect of methysergide on the vasoconstrictor actions of noradrenaline (NA), 5-HT, ATP and IMP. Open columns: untreated; hatched columns: treated with methysergide $(1 \mu \mathrm{g})$. N.S., not significant. Further explanation is in the text and Fig. 2. 
preparations.

Abolition by methyseroside of the vasoconstrictor Pesponse to tither ATP or IMP

As high doses of ATP or IMP which produce overt responses induced a lachyphylaxis, only a single dose of each was administered to a single preparation. In this conncction, in untreated preparations (Fig. 5A) noradrenaline $(0.1 / / 2), 5-\mathrm{HT}(1 / \mathrm{g})$ and ATP $(500 / / \mathrm{g}$ :

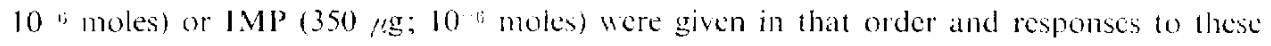
substances served as controls. The effect of methysergide was examined in other preparations in which noradrenaline and 5-HT were given prior to mehysergide, and noradrenaline, 5-HT and ATP or IMP were injected after methysergide in that order. As shown in Fig. 5A, a single injection of methysergide $(1 / \mathrm{g})$ into the femoral artery, which completely inhibited the vasoconstrictor response to 5 -HT $(1 \mu \mathrm{g})$ but not that to noradrenaline $(0.1$, , $)$, had almost no effect on the perfusion pressure. With the same dose of methysergide, the vasoconstrictor response to either ATP or IMP was almost completely blocked (Fig. 5A and B).

\section{DISCUSSION}

The present study revealed that when injected into the femoral artery of the rat, adenine nucleotides and IMP as well as adenosine and inosine caused proninent vasoconstrictions and that these responses showed marked tachyphylaxis. In the same sort of preparations, it has already been suggested that adenosine and inosine induce at vasoconstrictor response probably by releasing 5-HT from the peripheral stores, on the basis of the facts that the response disappared in both of the reserpine- and methysergide-treated preparations (7-8).

ATP is rapidly decomposed to adenosine or inosine via AMP or IMP by dephosphorylation in blood and tissues (9-11). It would be reasonable to suggest, therefore, that all the purines tested act as 5-HT releasers inducing vasoconstriction in the hindlimb of the rat. In fact, the vasoconstrictor responses to ATP and IMP, which were picked up out of six purines tested, were less prominent in reserpinized preparations as compared with that to the same doses of these substances in untrated preparations. Furthermore, the treatment with methyscrgide definitely blocked the constriction of femoral vasculature induced by ATP or IMP as well as 5-HT without preventing the vasoconstrictor effect of noradrenaline. These findings indicate that ATP and IMP as well as adenosine and inosine are potent releasers of 5-HT, regardless of the fact that the site from which 5-HT is released remains to be determined.

It should be emphasized that in order to release 5-HT from the peripheral storage site these substances must primarily enter the cell. However, a high phosphate conpound such as ATP, unlike adenosine and inosine, does not readily cross cell membranes (12 13). It seems likely, therefore, that exogenous nucleotides are brokon down to adenosine or inosine before taken up, in view of the evidence that nucleosides can readily pass 1 hrough cell membranes $(12,14)$.

The present results did not show at statistically' significant difference between the potencies of these substances inducing vasoconstriction. This can be explained on the basis that 
nucleotides are rapidly degraded to adenosine or inosine in blood and tissues.

From this study and the previous reports (7-8), it was concluded that all the purines tested produced a definite vasoconstriction indirectly by releasing 5-HT from the peripheral stores, and that the intrinsic vasodilator responses to these substances were probably masked by the predominent vasoconstrictor ones.

Acknowledgements: Sincere gratitude is extended to M. Akima for expert technical assistance, and to M. Hiruta and M. Onozawa for assistance in building the perfusion apparatus.

\section{REFERENCIS}

1) DRURY, A.N. A.ND Szent-GYorgyl, A.: The physiolngical activity of adenine compounds with especial reference to their action upon the mammalian heart. J. Physiol. 68, 213-237 (1929)

2) Folkow, B.: The vasodilator action of adenosine triphosphate. Acta physiol. scand. 17, $311-316(1949)$

3) BENNETT, D.W. AND DRURY, A.N.: Further observations relating to the physiological activity of adenosine compounds. $J$. Physiol. 72, 288-320 (1931)

4) Hashimoto, K., Kumakura, S. and Tanemura, I.: Mode of action of adenine, uridine and cylidine nucleotides and 2,6-bis-(diethanolamino)-4,8-dipiperidino-pyrimidino-(5,4-d)pyrimidine on the coronary, renal and femoral arteries. Arzneim.-Forsch, 14, $1252-$ $1254(1964)$

5) Hasilinoto, K. AND Kumakura, S.: The pharmacological features of the coronary, renal, mesenteric and femoral arteries. Japan. J. Physiol. 15, 540-551 (1965)

6) Sakat, K., Sugano, S., Tajra, N. and Hashimoto, K.: Pharmacological features of peripheral vascular beds of bcagles. Japan. J. Pharmacol. 24, 659-669 (1974)

7) SAKAI, K. AND AKIMA, M.: Tryptaminergic vasoconstriction induced by adenosine in the femoral vaseular bed of the rat. Japan. J. Phamacol. 27, 908910 (1977)

8) SAKAI, K. AND AKIMA, M.: Vasoconstriction after adenosine and inosine in the rat isolated hindlimb abolished by blockade of tryptaminergic mechanisms. Arch. Pharmacol. 302, 55-59 (1978)

9) Küler, W. AND BRETSCHNFider, H.J.: Kompetitive Henmung der katalysierten Adenosindiffusion als Mechanismus der coronarcrwcitcrnden Wirkung eines Pyrimido-pyrimidinDerivates. Pflügers Arch. 280, 141-157 (1964)

10) Rubio, R. AND BFRNF, R.M.: Relcase of adenosine by the normal myocardium in dogs and its relationship to regulation of coronary resistance. Circulation Res. 15, 407-415 (1969)

11) Bunnstock, G.: Purinergic nerves. Phamacol. Rev. 24, 509-581 (1972)

12) J.owY, B.A., DAvot., I. AND BROWN, G.B.: The utilization of purine nucleosides for nucleic acid synthesis in the rat. J. biol. Chem. 197, 591-600 (1952)

13) Hattori, E., MiYazaki, T. AND Nakamura, M.: Incorporation of adenosine and adenosine triphosphate into rat myocardium. Japan Heart J. 10, 47-52 (1969)

14) Whittam, R.: The high permeability of human red cells to adenine and hypoxanthine and their ribosides. J. Physiol. 154, 614-623 (1960) 